\title{
Ingvar Johansson and the Bridging Problem
}

Kristoffer Sundberg

\section{Introduction}

Ingvar Johansson's theory of perception is relevant to the contemporary debate in ways that have not been properly recognized. Johansson provides an ingenious solution to a problem that haunts some of the modern theories in the philosophy of perception. This problem, which I will refer to as "the bridging problem", has not been fully recognized in the contemporary debate, which might explain why Johansson's theory has not been given its due attention. My first goal will be to argue that there is a problem with some of the modern theories within the philosophy of perception. I will thereafter claim that Johansson's theory represents the only plausible response to this problem. In the end I will argue, perhaps surprisingly, that Johansson's theory is not preferable to, at least some, of the competing theories. This does not make Johansson's theory less relevant to the contemporary debate. On the contrary, by making explicit the consequences of one of the main contenders to a plausible theory of perception, it will potentially turn the tide in the contemporary debate.

\section{Disjunctivism and the Bridging Problem}

A theory known as disjunctivism is an increasingly popular theory within the philosophy of perception. Disjunctivism is a version of direct realism, i.e. a theory that claims that we are directly aware of objects and features of mind-independent reality when we perceive. Disjunctivism denies that veridical perception and hallucinations have an underlying mental state in common, despite introspective appearances to the contrary. ${ }^{1}$ Disjunctivism, as its name implies, takes a perceptual experience to be one of either a veridical perception or a state of hallucination. The main contender to disjunctivism is intentionalism which claims that perception, and other so called intentional acts, have a representational content, the satisfaction of which determines what object the act is

\footnotetext{
${ }^{1}$ Disjunctivists diverge on whether or not illusions, i.e. cases where an object is seen other than how it is, ought to be grouped with veridical perception or with hallucinations. I agree with A. D. Smith (2010) that illusions ought to be grouped with veridical perception, but we can afford to ignore this issue for now.
} 
referring to. ${ }^{1}$ Unlike disjunctivism, intentionalism claims that veridical perception and hallucinations have a common core since they could share the same type of content.

A version of disjunctivism, defended by Mike Martin, has been very influential, both amongst disjunctivists and amongst its opponents. ${ }^{2}$ The latter often take Martin's writings as the basis for criticism. It is not hard to see why Martin's writings on the subject have become so popular. Martin's version of disjunctivism provides ingenious, though controversial, solutions to some of the most common objections raised against disjunctivism. At the same time, Martin claims to supply a theory of perception that is described as an articulation of our common sense idea of perception, or as Martin calls it: naïve realism. Let us for the moment set aside the details of these objections to disjunctivism and Martin's replies to them. I am primarily interested in other aspects of Martin's theory.

Martin takes naïve realism to imply a theory where the perceived object is a constituent of the perceptual experience. Martin's writing is celebrated for the amount of detail he provides in defending disjunctivism against the common objections. But for all his attention to detail he does not seem to provide a proper explanation of what, more precisely, it means to say that a material object, i.e. the perceived object, is a constituent of a perceptual experience. The perceived object is usually a material object, while the perceptual experience is presumably a mental state. The perceived object is presumably "out there", i.e. in the external world beyond the body of the perceiver, while the perceptual experience is presumably "in here", i.e. inside the head at some ontological level.

Whatever a perceptual experience is, according to disjunctivism, it seems to be a far more complicated "thing" than what common sense suggests. Disjunctivism suggests that perceptual experience can be a "thing" that is both a mental state residing in the head of the perceiver, at some ontological level, while at the same time containing a material object, removed from the perceivers body, as a part. This paints a some-

\footnotetext{
${ }^{1}$ I am using "act" to refer to a real mental event existing in time, or in time and space, which is minimally dependent on the subject. I say "minimally" to allow for the possibility that the act also depends on the object to which it refers.

${ }^{2}$ Martin's disjunctivism is developed in several articles; see Martin (1997, 2002, 2004 and 2006).
} 
what counterintuitive picture of what kind of entity a perceptual experience is. Somehow it is an entity that is partly material and partly mental. There seems to be a need for a bridge between what prima facie seems material and external to what prima facie seems mental and internal. Let us refer to this as "the bridging problem".

Though much attention has been given to the details of Martin's defense against objections to disjunctivism, the bridging problem has not, to the best of my knowledge, been given enough attention. This is all the more serious since Martin relies on the idea that his theory of perception ought to be treated as our default view, i.e. as the theory that is closest to our common sense idea of perception.

Johansson has defended a theory of perception that is similar to Martin's in some respects. ${ }^{1}$ Much like Martin, Johansson claims that the perceived object is a constituent of the perceptual act, but, unlike Martin, Johansson spends considerable effort working out the ontological consequences of this claim. Given the great influence of Martin on the contemporary debate, and given the importance of working out the ontological consequences of this aspect of the theory, it is strange that Johansson's theory has not been given more attention in the debate. This text is to be seen as a small attempt to remedy this.

\section{Johansson's Theory of Perception}

Johansson defends a form of perceptual direct realism that is highly original, perhaps unique, where elements from both disjunctivism and intentionalism are brought together. For the present purpose it is Johansson's claim that the perceived object is a constituent of the perceptual act that is of primary interest.

\subsection{Johansson's Account of Intentionality}

Johansson develops his theory of perception within a general theory of intentionality, which in turn is developed within a general theory about the categories of reality. For Johansson, the capacity for intentionality separates subjects from objects. Intentionality has a "directedness", which means that "subjects can, thanks to their intentionality, 'point' beyond themselves in space and time" (Johansson 1989: 197).

\footnotetext{
${ }^{1}$ The theory is introduced in Johansson (1989: ch. 13) and developed in Johansson (1998).
} 
Following John Searle, Johansson claims that intentional acts directed at the world have a content which contains, or prescribes, a set of conditions; these conditions can be either satisfied or unsatisfied. ${ }^{1}$ Following Searle we can call this set of conditions "conditions of satisfaction" (Searle 1983:10). The conditions are satisfied if that which they describe exists. An utterance "there is a cat in my living room" is satisfied if and only if there is a cat in my living room. If I have a perceptual act of a cat in my living room the conditions of this act are satisfied if and only if there is a cat in my living room, where my perceptual act presents it as being. $^{2}$ A satisfied perceptual act is normally referred to as veridical perception.

Johansson has noted an ambiguity in Searle's use of "conditions of satisfaction" (Johansson 2003:246). On the one hand the term "conditions of satisfaction" might describe the set of conditions listed in the

\footnotetext{
${ }^{1}$ In fact, Johansson also argues that there is a subset of intentional acts, acts exhibiting fictional intentionality, which lacks this feature (Johansson 1989: 199). Claims about an object of fiction, e.g. the claim that Bilbo Baggins have an odd number of hairs on his head, are neither true nor false. For the present purpose we can afford to ignore this category since we are here strictly concerned with perceptual acts and their relationship to other world-directed intentional acts.

2 The story in the perceptual case needs to be elaborated, for it could be the case that I am simply having a hallucination of a cat in my living room, even though there is actually a cat precisely where I seem to see one. This is commonly referred to as a "veridical hallucination". It is usually assumed that veridical hallucinations must be distinguished from veridical perception by the addition of some requirement(s) to the conditions of satisfaction. A common strategy has been to incorporate causal factors into the account of veridical perception. The perceptual experience must be caused by the object that is presented in the conditions of satisfaction. Indeed, Searle claims that the conditions of satisfaction, or what we will soon refer to as "requirement conditions of satisfaction", explicitly mention the causal origins of the perceptual experience such that when I veridically perceive a yellow station wagon my act has the following content: "I have a visual experience (that there is a yellow station wagon there and that there is a yellow station wagon there is causing this visual experience)" (Searle 1983:48). The possibility of a disjunctivist theory of perception is sometimes taken to show that it is not a necessary, or a conceptual, truth that the perceived object must cause the experience. The details of what must be added to guarantee perceptual reference to the correct object is a controversial issue (see Fish 2010:113-123, for an overview of the debate). Paul Coates has claimed, contrary to what has sometimes been assumed, that this is a problem for disjunctivism, as well as for intentionalism (Coates 2007: chs. 3 and 4).
} 
content of the act. Compare this to a shopping list. The shopping list prescribes a number of items, e.g. bread, milk and coffee, which need to be added to the shopping basket for the shopping list to be satisfied. The term "conditions of satisfaction" may also describe those things in the world which functions to satisfy the conditions, e.g. the actual material bread, milk and coffee. Though Searle himself recognizes this ambiguity, between conditions of satisfaction as a requirement and as the thing required, he considers this ambiguity harmless (Searle 1983:13). Searle's continued use of the term "conditions of satisfaction" is sometimes vague because he does not explicitly define which way he uses the term. I will follow a suggestion from Johansson and distinguish between requirement conditions of satisfaction, which is the set of conditions listed in, or by, the intentional content, and required conditions of satisfaction, which are those things in the outside world which, if they exist, satisfies the act (Johansson 2003:246). Since intentional acts can be directed at a wide variety of phenomena, besides ordinary objects, Johansson recommends that we use the term "intentional correlate", rather than "intentional object", to signify that which intentional acts are directed at (Johansson 1989: 198). I will follow this suggestion.

When an intentional act is not satisfied it points towards a correlate, but there is no correlate such that it is pointed at by the act. The acts point in a certain direction, but there is nothing there to be the target of the act. To say of such acts that they point at nothing is in one sense correct, and in another incorrect. Using the distinction between requirement conditions of satisfaction and required conditions of satisfaction we can avoid the ambiguity. Unsatisfied intentional acts have requirement conditions of satisfaction, but lack required conditions of satisfaction. Satisfied intentional acts have both kinds of conditions of satisfaction. Saying that an unsatisfied act is directed at nothing is correct if we are referring to the required conditions of satisfaction and incorrect if we are referring to the requirement conditions of satisfaction.

\subsubsection{Representational and Presentational Intentionality}

Central to Johansson's account of perception is a distinction between two kinds of intentionality: representational intentionality and presentational intentionality. Perception is characterized by presentational intentionality while "such things as thoughts, uses of language, pictures and memories" (Johansson 1989:201) are characterized by representational 
intentionality. "In an utterance the intentional correlate is represented; in a perception it is presented" (Johansson 1989:202). Perception, Johansson notes, is direct in a way that other forms of intentional acts are not. Johansson is not alone in seeing a fundamental difference between perception and other intentional acts. Intentionalism has been criticized by disjunctivists and by philosophers defending sense-datum theories for not differentiating perception from other kinds of intentional acts (Crane 2011).

Johansson gives two similar, but not equal, accounts of what distinguishes presentational intentionality and representational intentionality from one another. The first account focuses on differences in the "claims" made by representational and presentational acts:

Presentational intentionality is characterized by its making a claim to directly present its intentional correlate. Representational intentionality is characterized by its making a claim not to present its intentional correlate directly; it claims to point to a correlate which is outside the intentional phenomenon itself. (Johansson 1989:202, italics in the original)

And again:

The characteristic feature of presentational intentionality is that it lays claim to be in direct contact with its correlate or, in other words, claims that the correlate is immanent in the act. It claims to include in itself that which it points at. (Johansson 1989:210)

If we are to understand the distinction we must know what "claims", "direct" and "include" means in this context. I will begin with the latter two.

The claim that an act is direct and the claim that it includes its intentional correlate could be understood as saying different things. After all, an intentionalist would claim that, at least de re, intentional acts stand in a direct contact with their correlate. The intentionalist objects that while the sense-datum theory posits an intermediate object as the immediate object of reference in perception, intentionalists claim that the intentional acts are mediated by a content, but that this content is not the intentional correlate. My thought about my personal copy of Ontological Investigations has that particular book as the direct correlate. The intentionalist would not, however, agree that the intentional correlate is in- 
cluded in the act as a genuine spatial part. The key to understanding Johansson's point is to remember that "direct contact" refers to spatial contact. That an act is directly about an intentional correlate is not enough for Johansson. For real contact to be made the contact must be made so that both correlates are spatio-temporally connected. The two notions, "direct contact" and "included as part", are therefore equivalent in Johansson's theory.

An intentional correlate is not presented directly if the correlate is "claimed" to be outside of the intentional phenomenon. The word "outside" refers to spatiotemporal distance from the act. The distinction between direct and indirect presentation of an intentional correlate then boils down to whether or not the intentional correlate is "claimed" by the act to be included within the act as a part: "misperception, like correct perception, claims to have an intentional correlate as a part of itself" (Johansson 1989:202). But what does it mean to say that an act "claims" that the intentional correlate either is, or is not, a part of the act? The most reasonable interpretation is that "claim", in this context, refers to the act's requirement conditions of satisfaction. That means that Johansson takes presentational intentional acts to include amongst their requirement conditions of satisfaction the notion that the intentional correlate is a part, or as we have been calling it previously, a constituent, of the act itself. If this interpretation of Johansson is correct the requirement conditions of satisfaction when perceiving a black cat would include the following requirement: "I perceive a black cat and the cat is a part of my intentional act".

At other times Johansson draws the distinction between representational and presentational intentionality based on whether or not the intentional correlate actually is a part of the act, rather than based on whether or not the act "claims" to include the correlate as a part. Satisfied representational acts are said to have transcendent correlates, i.e. the correlate is not included as a part of the act, while satisfied presentational acts are said to have immanent correlates, i.e. the correlate is included in the act as a part (Johansson 1989:212).

One difference between these two ways of drawing the distinction is that drawing the distinction based on the "claims" made by the acts, i.e. based on their requirement conditions of satisfaction, allows for a distinction to be made between unsatisfied presentational intentionality 
and unsatisfied representational intentionality. Drawing the distinction based on whether the intentional correlate transcends the act or is immanent in the act, only works for satisfied intentional acts, since both forms of real intentionality will lack a correlate when unsatisfied.

So, which of the two ways of drawing the distinction between representational intentionality and presentational intentionality is the primary one? An example from Johansson implies that the distinction between presentational and representational intentionalism ought to be drawn based on the requirement conditions of satisfaction, rather than based on the actual object in the world that satisfies the conditions, i.e. the required conditions of satisfaction.

Assume, now, that you believe yourself to see a wax doll representing a certain person in spite of the fact that what you actually see is the real person. This is an example of representational not of presentational intentionality, because the intentional act is such that it claims to have its intentional correlate outside itself, in spite of this not being the case. (Johansson 1989:202f.) ${ }^{1}$

In this example the person is actually seen and is therefore included in the act but the "claims" made by the act denies this. Since Johansson nevertheless describes this as a representation, rather than a presentation this shows that Johansson primarily categorizes the intentional act according to the "claims" made by it, i.e. by its requirement conditions of satisfaction.

Another important point mentioned by Johansson is that we are only ever directly presented with the surface of the object facing us. The object itself has other sides than the one not facing us. It has also got an

\footnotetext{
${ }^{1}$ But this example is problematic. Taken as a representation of the specific person, as a pictorial awareness of said person, the act could plausibly be described as a representation. However, the perceptual awareness directed at the wax doll is a perceptual act which directly presents the wax doll. These kinds of examples, involving objects with representational powers, seem to involve two kinds of awareness. On the one hand the portraying media, i.e. the wax doll, is directly presented, while the object that it represents is indirectly represented by the subject through, or mediated by, the portraying media. That would mean that one act, the act of directly perceiving the wax doll, presents the correlate (the wax doll) as a part of the act, while the other act, the act of representational intentionality directed at the person who is portrayed by the wax doll, represents the correlate as located outside of the act.
} 
interior that is usually hidden from us. Johansson's distinction between presentational and representational lets him postulate acts characterized by mixed intentionality (Johansson 1989: 204f.). The surface of the object facing us is presented, whereas the rest of the perceived object is merely represented.

\subsection{Perceptual Acts Extending Beyond the Confines of the Perceivers Body}

So far we have learned that perception is characterized by presentational intentionality and this means that the act, if satisfied, contains the intentional correlate as a part (constituent). Though this account has some advantages over Martin's account, such as leaving room for mixed intentionality, we still have not learned what it means to say that a perceptual act have an intentional correlate as a part of itself. This was the challenge left by Martin, what we referred to as "the bridging problem", and the primary motivation for examining Johansson's theory of perception.

Johansson argues that we must accept that intentionality, though existing on a "higher" ontological level than material objects, is located in time and space (Johansson 1989:221). A dreamer's dream is located in the exact same place as the dreamer's brain, though on a higher ontological level. The question then remains whether or not acts can also be in spatial contact with correlates outside of the subject's body. Johansson posits that acts of presentational intentionality are extended in space outside of the perceiver's body to include the intentional correlate as a part of itself. The bridge between what is prima facie taken to be internal, i.e. our intentional act, and what is prima facie taken to be external, the intentional correlate, is bridged by denying that the intentional correlate is external to the act and by denying that the act is wholly internal to the perceivers body. A veridical perceptual act is a complex entity, according to Johansson, containing at least three parts: first of all the "subject pole of the act", which is Johansson's term for the part of the subject that figures in the act, secondly the intentional correlate, and finally an external relation of spatial distance (Johansson 1989:210f.).

But not only do presentational intentional acts span the spatial distance between the subject and the intentional correlate. Because of the finite speed of the transmitting media, e.g. light and sound waves through air: 
[W] have to accept that intentionality which is connection at a spatial distance is also connection at a temporal distance. When we perceive a thing, we do not perceive it as it is now. We perceive it the the [sic] way it was structured when the relevant energy (according to Gibson: electromagnetic radiation with stimulus information) left the thing. (Johansson 1998: 127)

Johansson's notion of "connection" implies that the act spatially includes its correlate. This in turn means that the perceptual act stretches out through time and space beyond the subject's body. When perceiving distant objects like stars our perceptual acts are entities stretching out millions of light-years and years from where and when the subject's body is at the time of the perceptual experience.

This paints a rather curious picture of the nature of our perceptual mental states. Indeed, it suggests a somewhat counterintuitive view of us as subjects, i.e. of our egos. Johansson, well aware of this, describes the consequence of his theory as follows:

In veridical perception the ego is fused with natural facts, and the spatial limits of the ego are the spatial limits of its intentional acts. Wherever an intentional act turns the non-perceiving of material things into perceiving, the spatial limit arises. The ego is not spatially confined to its body in spite of the fact that its intentional acts are existentially dependent upon the body. Intentionality makes the ego spatially undetermined. Normally, the limits of our ego are changing. At one moment we are looking at states of affairs close to us, and at the next moment we are looking at more distant states of affairs. (Johansson 1998: 131f.)

Johansson admits that this is odd but nevertheless claims that there are reasons for preferring this theory to the alternative.

\subsubsection{Denying Presentational Intentionality Invites a Monadology}

What is the alternative to Johansson's theory? According to Johansson the only option that remains, if we deny his theory, is a theory aching to Lebniz' monadology.

Within contemporary science one assumes that there are material things which emit or reflect some form of energy which moves towards other material things, some of which are so constituted (the higher animals) that when the aforementioned energy hits them, a 
mental entity appears on the scene, a perception. But this perception is presumed to be completely spatially distinct from the material object which ultimately caused the perception [...]. The perception is connected via a body to a certain place in space and time, but is whole completely closed within itself, which is mental and does not even have a spatial connection with other people's perceptions, even though they often have the same causes. Every person is a monad, on this view, though a monad with a material foundation. (Johansson 1989:217)

It is often assumed that a theory of perception is direct realist if it does not posit any mediate object between the perceiver and the object perceived. Johansson's notion of direct realism demands something stronger. For real contact to be made, Johansson demands that there is spatial contact between the act and the intentional correlate. The problem is not that the mind is mental, while the external world is material, as can be seen from Johansson's critique of Searle:

Applied to kissing and other nice things done intentionally together with a beloved one, Searle's analysis means the following. In such situations one's material body is literally in spatial contact with the beloved's body, but one's perceptions are wholly in one's own head, and the beloved's perceptions are wholly in the beloved's head. My mind is mine and her mind is hers, and never do they meet; not even partially! (Johansson 2003:249)

Again, the crucial idea is that spatial contact is demanded of any theory that is to be described as direct realism. This explains why Johansson, despite admitting that his own theory is in some respects counter to common sense, nevertheless argues that it ought to be preferred as the less "costly" alternative:

As far as I can see, our fallibilist ontological choice today consists, to put it sharply, in either accepting a monadology or accepting a direct realism which contains the peculiarities of connection at distance, $\mathrm{x}$ ray perception, backward perception and undetermined limits of the 
ego. In my opinion, the monadological alternative is more incredible than direct realism with its implications. (Johansson 1998: 135) ${ }^{1}$

Much like Martin, Johansson argues that the view that the intentional correlate is a constituent of the act ought to be considered our default view. If we are to assess which theory is the simplest, or least costly, and therefore ought to be considered our default view, we must fully examine both Johansson's own theory, as well as the various alternatives. The assessment of the alternatives in light of Johansson's critique is an interesting project, but this is beyond the scope of the present paper. No matter if we agree with Johansson or not in his assessment of which theory is simpler, I believe that the cost involved in positing material mind-independent objects as constituents of the act needs to be made explicit. This has not been done in the contemporary debate. This is especially urgent with respect to Martin's theory. Before making a tentative judgment as to whether we ought to accept Johansson's theory as our default view, I will first examine some internal problems with Johansson's theory.

\section{Problems with Johansson's Theory}

Despite the great merits of Johansson's carefully worked out ontological framework, there are some internal problems with his theory.

\subsection{Problems with Johansson's Definition of Presentational Acts}

Johansson's theory of perception is built on his distinction between representational intentionality and presentational intentionality. Were his theory of intentionality to consist strictly of representational intentionality, his theory would be no different from intentionalism. ${ }^{2}$ The crucial question then boils down to this: is there, besides representational

\footnotetext{
${ }^{1}$ Johansson's point about x-ray perception is simply the observation that we often perceive through transparent material substances such as air, windows, and water.

${ }^{2}$ It is difficult to say if Johansson's theory could be considered a version of disjunctivism even if we allow for presentational intentionality. At times Johansson seems to accept that veridical perception and hallucinatory perception could share the same content. If this is correct his theory is a highly original version of, what Alex Byrne and Heather Logue refers to as, "the moderate view". The moderate view claims that, though there are important differences between veridical perception and non-veridical perception, they share a common core. See Byrne and Logue (2009: $x$ ) for a discussion of the moderate view.
} 
intentionality, presentational intentionality? One possible argument for Johansson's theory of presentational intentionality could be made based on the difference between perception and all other forms of intentionality. In perception we are directly and involuntarily given the conditions of satisfaction. This is not the case in other forms of intentional acts, and Johansson's theory can explain this. Searle also makes a distinction between presentations and representations, but he does not seem to have the resources to fully explain why they are different (Searle 1983:46f.). Johansson's theory seems to have an advantage, but I want to highlight a potential problem with the way Johansson draws the distinction between representations and presentations.

Whereas Johansson claims that the inclusion of the intentional correlate as a part of the perceptual act is an explicit part of the requirement conditions of satisfaction, Searle has argued that the causal origin of the perceptual experience is part of the explicit requirement conditions of satisfaction. A. D. Smith has argued that the problem with Searle's inclusion of the causal factors in the explicit intentional content, i.e. in the requirement conditions of satisfaction, is that it is phenomenologically false (Smith 2002: 121). Indeed, this has been a common objection against Searle's theory. It seems to me that the same objection could be made against Johansson's account: it is not phenomenologically accurate to say that the perceptual content explicitly mentions that the correlate is a part of the act. In fact, I predict that most people would be surprised to learn of this.

This is even more obvious when considering that perception is not purely presentational. As an example of mixed intentionality Johansson describes a case where we perceive a man $C$ who is digging.

When we perceive $C$ 's digging we see that we see only one side, the outside of $C$ and the shovel. The perception makes the claim that parts of these things are presented, but at the same time it makes the claim that other parts are represented. It contains a pointing to facts of the type that both $C$ and the shovel have back-sides, insides, and so on. $C$ 's digging is thus not completely presented even if we disregard its temporal extension. Such a perception contains a mixture of presentational and representational intentionality. The presentation of the thing is only partial, part of the thing is represented by means of its presentation of other parts. (Johansson 1989:204) 
If the word "claim" is interpreted as referring to the requirement conditions of satisfaction, then this means that the requirement conditions of satisfaction explicitly mentions the fact that the surface facing the perceiver is included in the perceptual act as a part. It would also mean that the requirement conditions of satisfaction explicitly mentions that the rest of the object is not included as actual parts of the act, but are nevertheless pointed at by the act. I find this even more phenomenologically dubious.

What I find dubious is not the fact that we only directly perceive one side of the perceived object. What is implausible is, rather, Johansson's claim that the perceptual content explicitly "claims" to include, as a constituent, the surface of the side of the perceived object facing the subject, while also explicitly "claiming" not to include the rest of the perceived object. When asked what we see we seem inclined to answer simply in terms of what objects and events we see. We usually do not pay attention to the fact that we are only directly aware of the surface facing us. Nor are we inclined to mention that the surface of the object is a constituent of our perception, while the rest of the object is not. This does not imply that it is impossible that the surface of the perceived object, but not the rest of the object, actually is a constituent of the perceptual experience. But it does cast doubt on whether such notions are included in the explicit perceptual content. If my interpretation of Johansson's use of the word "claim" in defining presentational intentionality is correct, then Johansson's position seems to get the phenomenology of visual perception wrong.

I do agree with Johansson that there are good reasons for distinguishing presentational intentionality from representational intentionality. I do, however, see another potential problem in drawing the line between presentational intentionality and representational intentionality based on the requirement conditions of satisfaction. This way of drawing the distinction could, given bizarre circumstances, potentially lead to the inclusion of typical representational intentional states, e.g. beliefs or utterances, amongst the category of presentational intentionality. Consider a case where a deranged man comes to represent an external object as a constituent of his beliefs. Mistakenly he comes to believe that his thoughts have the power to traverse the spatiotemporal distance between him and the objects of thought. An explicit part of the intentional content 
would then be a "claim", in Johansson's sense of the word, that the external object is a constituent of the intentional act. According to Johansson's definition of presentational intentionality this would render the deranged person's beliefs as unsatisfied presentational acts. This does not seem right since the objects of belief are not directly and involuntarily presented in the way that the objects of perception are. What we need is a way of drawing the distinction between presentational and representational intentionality that guarantees that perception is different in kind from non-perceptual intentional acts such as states of beliefs.

An alternative would be to claim that perception, but not belief, has a distinct sensory character and that it is this, and not the required conditions of satisfaction suggested by Johansson, that differentiates perception from thought. A. D. Smith has suggested that perception contains a sensory component that is lacking in other forms of intentionality.

[W] hat cannot sensibly be denied is that some such inclinations and not others have a sensuous character. Seeming to see something yellow differs qualitatively, as an experience, from merely having a hunch that there is something yellow before one. (Smith 2002:47)

A similar account is given by Paul Coates: "Thoughts, but not perceptions, could be said to be genuinely transparent. What is a thought other than the content (object) of the thought? It does not have a distinct feel over and above the content of the thought" (Coates 2007:41). It seems to me that this suggestion is less "costly" than Johansson's suggestion that perceptual acts differ from other intentional acts by being presented as extended in time and space to encompass the intentional correlate. It also seems to be more in accordance with the phenomenology of perception.

Another potential problem concerns the relationship between Johansson's definition of intentionality, as a determinable, and his definition of presentational intentionality. As was mentioned previously, Johansson defines intentionality as a capacity of subjects to point beyond themselves. "But subjects can, thanks to their intentionality, 'point' beyond themselves in space and time" (Johansson 1989: 197). No doubt, this description of intentionality is accurate for representational intentionality. But Johansson claims that presentational intentional acts are extended so as to include the correlate they are directed at. This gives rise to the "changeful limits of our ego" (Johansson 1998: 129). This seems to 
contradict the notion that subjects, in presentational intentionality, points beyond themselves since these acts include that which they point towards. If Johansson's definition of intentionality is taken literally then it seems that satisfied presentational intentional acts are not, after all, intentional. The definition of intentionality, as a determinable, or the definition of presentational intentionality must be altered.

\subsection{Perception Cross Time and the Ontology of Time}

Another potential problem for Johansson's theory concerns the ontology of time. Sometimes Johansson seems to imply presentism, i.e. the view that only the present exists.

In order for the perception itself to occur, the energy transport must have reached the subject substratum, which means that when perceptions of the state of affairs in question occur that state of affairs no longer exists - the transport of energy takes time. (Johansson 1989: 222, my italics)

And again: "The difficulty with 'intentionality through time' in comparison with 'intentionality through space' is that in the first case, but not in the second, one is in contact with something which no longer exists" (Johansson 1989:223, my italics). Johansson foresees objections to his account based on the difficulty of accepting material objects as actual parts of intentional acts. However, the idea that non-existent material objects, or states of affairs, can be real parts of existing mental states must be considered even more controversial. Since Johansson relies on abductive justification for his theory, i.e. that his theory ought to be preferred based on it being the simplest account and most in line with common sense, this is a pressing issue. Theories positing non-existent objects must be seen as a departure from common sense and should therefore be avoided unless we are forced to accept them.

But Johansson can easily avoid any reference to non-existent objects as long as he avoids strict presentism. If so, perception still involves a connection across a temporal and spatial distance. But no longer does it connect what exists to what does not exist. As long as presentism is denied, Johansson's theory simply implies that perceptual acts extend from one spatio-temporal coordinate to another spatio-temporal coordinate. 


\section{Conclusion}

I do not share Johansson's doubts about locating intentional acts entirely within the subject's body. Perhaps there are some finer details about the argument that I have failed to grasp. Perhaps our intuitions diverge. The fact, if it is a fact, that my experience of the world is within me, in some sense of the word "within", while the objective reality that I observe is outside of me, is no threat as long as we do not posit intermediate objects between the experience and the world. According to intentionalism my experience, though private, is immediately an experience of, or about, the external world. Even though my experience is located within me, it can, thanks to its intentionality, point beyond itself. This should not come as a surprise for Johansson since he admits that there is, besides presentational intentionality, representational intentionality. Why is it that representational intentionality is good enough for other kinds of intentional acts, but not good enough for perception? One reason has already been mentioned: perception is more direct and involuntary than other forms of intentionality. Though this is undoubtedly true there might be better answers as to why perception is different. Indeed, I have already argued that the alternative account provided by Smith and Coates is preferable to Johansson's account.

Why then, if I do not accept his conclusion, do I spend so much time advocating Johansson's theory about perceptual acts as extended in time and space? I believe that as a matter of intellectual honesty one must openly account for all the "costs" involved in a proposed theory. Johansson, to his great merit, admits, and explicitly explains, why his proposal is counterintuitive. Compared to the alternatives he argues that we still ought to accept his theory. I have my doubts on this last account. I also believe that others will have doubts upon knowing the full consequences of this theory. I have claimed that Martin's disjunctivism entails Johansson's theory about acts extended in time and space beyond the subject's body, given that Johansson's theory is the only available solution to the bridging problem. Martin and Johansson both rely on abductive justifycation. While Johansson makes explicit the cost involved in accepting this theory, Martin brushes over these important questions. Johansson's 
writing on the subject is therefore highly relevant to the contemporary debate in the philosophy of perception. ${ }^{1}$

\section{References}

Byrne, Alex, \& Logue, Heather (eds.) (2009). Disjunctivism: Contemporary Readings, Cambridge, Mass.: MIT Press.

Coates, Paul (2007). The Metaphysics of Perception: Wilfrid Sellars, Perceptual Consciousness and Critical Realism, London: Routledge.

Crane, Tim (2011). "The Problem of Perception", The Stanford Encyclopedia of Philosophy (Spring 2011 Edition), Edward N. Zalta (ed.),

URL $=<$ http://plato.stanford.edu/archives/spr2011/entries/perceptionproblem/>

Fish, William (2010). Philosophy of Perception: A Contemporary Introduction, New York: Routledge.

Martin, M. G. F. (1997). “The Reality of Appearances”, in M. Sainsbury (ed.), Thought and Ontology, Milan: FrancoAngeli, 81-106.

Martin, M. G. F. (2002). "The Transparency of Experience", Mind \& Language, 17:376-425.

Martin, M. G. F. (2004). “The Limits of Self-Awareness", Philosophical Studies, 120: 37-89.

Martin, M. G. F. (2006). “On Being Alienated”, in Tamar S. Gendler \& John Hawthorne (eds.), Perceptual Experience, Oxford: Clarendon Press, 354-410.

Johansson, Ingvar (1989). Ontological Investigations: An Inquiry into the Categories of Nature, Man and Society, London: Routledge.

Johansson, Ingvar (1998). "Perception as the Bridge Between Nature and Life-World", in C. Bengt-Pedersen \& N. Thomassen (eds.), Nature and Life-World, Odense: Odense University Press, 113-137.

Johansson, Ingvar (2003). "Searle's Monadological Construction of Social Reality", American Journal of Economics and Sociology, Special Invited Issue: John Searle's Ideas about Social Reality: Extensions, Criticisms, and Reconstructions, 62:233-255.

\footnotetext{
${ }^{1}$ I am grateful to Jan Almäng and Susanna Salmijärvi for comments on previous versions of the paper.
} 
Searle, John R. (1983). Intentionality: An Essay in the Philosophy of Mind, Cambridge: Cambridge University Press.

Smith, A. D., (2002). The Problem of Perception, Cambridge, Mass.: Harvard University Press.

Smith, A. D. (2010). "Disjunctivism and Illusion", Philosophy and Phenomenological Research, 80:384-410. 